\title{
Craniofacial Morphology of Class II Division 1 Nepalese Population.
}

Manish Bajracharya ${ }^{1}$, Umesh Parajuli ${ }^{2}$, Praveen Mishra ${ }^{3}$, Prakash Bhattarai ${ }^{4}$, Reetu Shrestha ${ }^{5}$.

${ }^{1}$ Dental Department, Sri Birendra Hospital, ${ }^{2}$ Orthodontic and Dentofacial Orthopedics Department, Gandaki Medical Collage, ${ }^{3}$ Orthodontic Department, Bir Hospital, ${ }^{4}$ Orthodontic Department, Nepal Medical College, ${ }^{5}$ Endodontic Department, Kathmandu University School of Medical Sciences.

\begin{abstract}
Introduction: Class II Div 1 is a deviation from normal occlusion and may arise from combination of different craniofacial components. The objective of this study was to find out the different possible dental and skeletal components that lead to Class II Div 1 malocclusion in Nepalese population. Methods: The lateral cephalogram radiographs consisted of 30 males and 30 females between the age group of 18 to 32 years. All the radiographs were traced with hand on acetate paper sheets. All the landmarks were identified, located and marked. Steiner's analyses and McNamara analysis were done for the cephalometric measurements. The mean values were obtained and were compared with the established available values of the Nepalese and Caucasian norms using independent t-test. Results: Size of the mandible was found to be lesser than the established normal values. Prognathic maxilla with retrognathic upper incisors and retrognathic mandible with proclined lower incisors and was found to be the most common combinations of Class II Div 1 component. Conclusion: Size of the mandible is less than the normal value which is the main cause of the Class II Div 1 pattern in Nepalese population.
\end{abstract}

Keywords: class II div 1, nepalese population, steiner's analysis, mcnamara analysis

\section{INTRODUCTION}

Class II division 1 malocclusion is significant deviation from normal occlusion and has been defined by angle as a distal relation of the lower teeth to the upper to the extent of more than one- half the width of one cusp and the maxillary incisors being protrusive ${ }^{1}$. It can be due to aberrations in skeletal or dental components in maxilla, mandible or both².

Cephalometric norms for different ethnic and racial groups have previously been established in many studies ${ }^{3-6}$. Most investigators have concluded that there are significant differences between the diverse ethnic and racial groups, and many cephalometric standards have been developed for different ethnic groups ${ }^{7-9}$. All these studies indicate that normal measurements for one group should not be considered normal for every other race or ethnic group. Different racial groups must be treated according to their own characteristics.
Many studies have attempted to clarify the morphological features of skeletal Class II malocclusion. No researches have been done in the Nepalese population. So the purpose of this study was to analyze different components of class II in the Nepalese population.

\section{METHODS}

The lateral cephalograms were screened and those meeting the inclusion criteria for Class II Div 1 malocclusions were randomly chosen such that there were 30 males and 30 females. Patients with skeletal class II with ANB at least 4 degrees having full complement of teeth with the exception of third molars without any congenital and dentofacial abnormalities were included in this study. Patients with missing, extracted or supernumery teeth, history of previous orthodontic and prosthodontic treatment, disfigurement of face due to trauma and periodontal problems were excluded from the study.

\section{Correspondence:}

Maj. Dr. Manish Bajracharya

Dental Department, Sri Birendra Hospital,

Kathmandu, Nepal.

Email: manishbajracharya@gmail.com

Phone: +977-9841335537 
The radiographs consisted of 60 cases involving 30 males and 30 females between the age group of 18 to 32 years. The age group was chosen such that the growth has been completed by that age. All the radiographs were taken such that the subjects were positioned with spines erect. Cephalometric radiographs were taken with teeth in maximum intercuspation and lips relaxed in Natural head position. The cephalostat used were Rotagraph plus model MR05. Focus film distance was 1.65 inch and focus patient distance was 1.5 meters or 59 inch. All the radiographs were taken with exposure maintained at $85 \mathrm{kVp}$ and current $10 \mathrm{~mA}$ with filtration of $2.5 \mathrm{~mm}$ of Al.eq.

All the radiographs were traced with hand on acetate paper sheets. All the landmarks were identified located and marked. The located landmarks were verified by both the authors. All the measurements were obtained with the help of vernier caliper (Mitutoyo SER No.60325791, Japan) for linear measurements and protractor for angular measurements which recorded up to $0.02 \mathrm{~mm}$ and 0.5 degrees respectively. All these tracing were done by the same operator in order to avoid inter-examiner variability.

Steiner's analysis and McNamara analysis were done. The data obtained were entered in SPSS (statistical package for social science) program version 17 (SPSS Inc, Chicago, III). The mean values obtained and were compared with the established values of the Caucasians and the Nepalese norms wherever applicable. The comparison was done by independent $\mathrm{t}$-test. The $\mathrm{P}$-values were calculated under the predetermined level of significance of 0.05 and the confidence level (CI) of $95 \%$.

\section{RESULTS}

The mean, standard deviations and statistical differences for linear and angular measurements of class II samples and their comparison with the Caucasians and Nepalese are presented in tables. The mandible was found to be placed posteriorly when compared to established Nepalese norms which is the main cause of the Class II Nepalese population ( $\mathrm{SNB}=77.53 \pm 1.55, \mathrm{P}<0.001)$. Maxilla was found to be in normal position in comparison to the Nepalese norms $(\mathrm{SNA}=83.16 \pm 1.60, \mathrm{P}=0.767)$. Maxillary anterior teeth were found to be more protruded and proclined (Upper incisor to NA linear $6.30 \pm 2.11, \mathrm{P}=0.012$ and Angular 27.38 \pm 4.47 , $\mathrm{P}<0.001$ ) where as the mandibular anterior teeth was found to be normal position but proclined (Lower incisor to NB linear $6.65 \pm 2.01, \mathrm{P}=0.196$ and angular $29.93 \pm 5.26$, $\mathrm{P}<0.001)$. It was found that Class II malocclusion is not characterized by a single entity and it can result from various combinations of skeletal and dental inter-relationship.
Table 1. Comparison of class II Nepalese with the Caucasian normal.

\begin{tabular}{|lcccc|}
\hline $\begin{array}{l}\text { Cephalometric } \\
\text { measurements }\end{array}$ & $\begin{array}{c}\text { Caucasian } \\
\text { Normal }\end{array}$ & \multicolumn{2}{c|}{ Class II Nepalese } & p Value \\
\hline SNA $\left(^{\circ}\right)$ & 82.00 & 83.10 & 1.60 & $<0.01$ \\
\hline SNB $\left(^{\circ}\right)$ & 80.00 & 77.53 & 1.55 & $<0.01$ \\
ANB $\left(^{\circ}\right)$ & 2.00 & 5.61 & 1.85 & $<0.01$ \\
GoGn to SN $\left(^{\circ}\right)$ & 32.00 & 24.80 & 3.96 & $<0.01$ \\
\hline $\begin{array}{l}\text { Upper Incisor to NA }\left(^{\circ}\right) \\
\text { Upper Incisor to NA }\end{array}$ & 22.00 & 27.38 & 4.47 & $<0.01$ \\
(mm) & 4.00 & 6.30 & 2.11 & $<0.01$ \\
Lower Incisor to NB $\left(^{\circ}\right)$ & 25.00 & 29.93 & 5.26 & $<0.01$ \\
Lower Incisor to NB & 4.00 & 6.65 & 2.01 & $<0.01$ \\
\hline$(m m)$ & & & & \\
\hline
\end{tabular}

Table 2. Comparison of class II Nepalese with the Nepalese Norms.

\begin{tabular}{|c|c|c|c|c|}
\hline \multirow{2}{*}{$\begin{array}{l}\text { Cephalometric } \\
\text { measurements }\end{array}$} & \multirow{2}{*}{$\begin{array}{l}\text { Nepalese } \\
\text { Normal }\end{array}$} & \multicolumn{2}{|c|}{ Class II Nepalese } & \multirow[t]{2}{*}{ p Value } \\
\hline & & Mean & SD & \\
\hline SNA $\left(^{\circ}\right)$ & 83.17 & 83.10 & 1.60 & NS \\
\hline SNB $\left(^{\circ}\right)$ & 79.76 & 77.53 & 1.55 & $* * *$ \\
\hline ANB $\left({ }^{\circ}\right)$ & 3.42 & 5.61 & 1.85 & $* * *$ \\
\hline GoGn to $\mathrm{SN}\left({ }^{\circ}\right)$ & 27.91 & 24.80 & 3.96 & $*$ \\
\hline Upper Incisor to NA $\left({ }^{\circ}\right)$ & 21.32 & 27.38 & 4.47 & $* * *$ \\
\hline $\begin{array}{l}\text { Upper Incisor to NA } \\
\text { (mm) }\end{array}$ & 5.59 & 6.30 & 2.11 & $*$ \\
\hline Lower Incisor to NB ( $\left.{ }^{\circ}\right)$ & 26.26 & 29.93 & 5.26 & $* * *$ \\
\hline $\begin{array}{l}\text { Lower Incisor to NB } \\
(\mathrm{mm})\end{array}$ & 6.31 & 6.65 & 2.01 & NS \\
\hline
\end{tabular}

\section{DISCUSSION}

Maxillary skeletal position: SNA and effective maxillary length were taken into consideration. The SNA value in this study indicates that the maxilla is prognathic when compared to the Caucasian. (Table 1). However, it is not significantly different in comparison to the Nepalese norms of 83.17 degrees (Table 2). The effective maxillary length in both males and females is found to be significantly less than the norms of the Caucasians (Table 3 and 4). The effective maxillary length of the males class II samples were significantly more than the class II female samples (Table 5). The findings of the above results show that, the maxilla is in normal position in majority of the cases of class II Nepalese patients. This finding is in agreement with Riedel ${ }^{10}$ who found that there is no significant difference between anterio-posterior position of the maxilla in relation to the cranial base in patient presenting with class II malocclusion and normal occlusion. Hunter ${ }^{11}$ found similar result. He concluded that the maxilla is in normal position. This study however contradicts the results obtained by Altemus ${ }^{12}$, Delich ${ }^{13}$, Rothstein ${ }^{14}$, Khateeb et $\mathrm{al}^{15}$ and Arnold M Reismeijer ${ }^{16}$. Their results show that there is an anterior positioning of the maxilla relative to other craniofacial components. Similarly, studies done by Henry $^{17}$ and Harris et al ${ }^{18}$ indicated that the maxilla in average is in slight retrusive and SNA angle of their class II sample averaged 1.5 less than class I mean with which class 
II was compared.

Maxillary dental position: Upper incisor to NA both angular and linear measurements and upper incisor to point $\mathrm{A}$ was measured. It was found that upper incisors are more proclined and protruded in our sample in comparison to the Caucasians, and Nepalese norms (Table 1 and 2). When class II males and females are taken into consideration, it is seen that females have more protruded upper incisors than the males as dictated by upper incisor to point A parameter, though the difference is not statistically significant (Table 5). Riedel ${ }^{10}$ in his study also found that maxillary incisors were protruded than the patients having normal occlusions. Hitchcock ${ }^{19}$ also found that similar results that the maxillary incisor proclination as well as protrusion than the normal class I samples.

Mandibular Skeletal position: SNB and effective mandibular length were measured. The results showed that the mandible is retrognathic in position. SNB value in this study sample is 2.23 degrees less than that of the class I norms (Table 1 and 2). Effective mandibular length is smaller than the Caucasian for both males and females (Table 3 and 4). However, the maxilla-mandibular difference is not statistically significant when males and females are compared (Table 5). Craig ${ }^{20}$ reported that the mandibular body was shorter in class II cases. However Rothstein ${ }^{14}$ and Adams ${ }^{21}$ stated that absolute length of the mandible in class II cases did not differ from those of Class I subjects which are in contradiction to our study in which we found that the length of the mandible is shorter in comparison to the Caucasians. Altemus ${ }^{12}$ reported that in general mandible was slightly longer in class II patients than in class I. Henry ${ }^{17}$ and Reinfroe ${ }^{22}$ noted that certain class II patients could be characterized as being deficient in mandibular size, other class II patients had mandibles that are well formed but were retruded due to posterior position of the glenoid fossa.

Mandibular dental position: To relate mandibular dental position, lower incisor to $\mathrm{NB}$ both angular and linear measurements and lower incisor to A-Pog were taken into consideration. Lower incisor to NB showed that the lower incisors are more proclined and more protruded by 4.93 degrees and $2.65 \mathrm{~mm}$ respectively compared to Caucasians (Table 1). When compared to Nepalese norms, it was seen that lower incisors are more proclined by 3.67 degrees which is statistically significant (Table 2). The position of the lower incisors though protruded is not statistically significant when compared to Nepalese norms. Lower incisor to A-Pog shows that the lower incisors are protruded in both males and females when compared to the Caucasians norms (Table 3 and 4).
Table 3. Comparison of class II Nepalese Males with the Caucasian Normal.

\begin{tabular}{lllll}
\hline Parameters & $\begin{array}{l}\text { Caucasian } \\
\text { Normal }\end{array}$ & \multicolumn{2}{l}{ Class II Nepalese } & P Value \\
& & Mean & SD & \\
$\begin{array}{l}\text { Effective maxillary } \\
\text { Length (mm) }\end{array}$ & 99.80 & 96.86 & 3.90 & $* * *$ \\
$\begin{array}{l}\text { Effective mandibular } \\
\text { length (mm) }\end{array}$ & 134.3 & 124.10 & 4.49 & $* * *$ \\
$\begin{array}{l}\text { Maxillo - mandibular } \\
\text { difference (mm) }\end{array}$ & 34.50 & 27.23 & 4.71 & $* * *$ \\
$\begin{array}{l}\text { Upper Incisor to } \\
\begin{array}{l}\text { Point A (mm) } \\
\text { Lower incisor to A - }\end{array}\end{array}$ & 5.30 & 6.03 & 1.09 & $* *$ \\
Pog (mm) & 2.30 & 6.33 & 3.69 & $* * *$ \\
\hline
\end{tabular}

${ }^{\star} \mathrm{P}<.05 ;{ }^{* *} \mathrm{P}<.01 ;{ }^{* *} \mathrm{P}<.001$. Sig indicates significance; NS, not significant

Taking into consideration the Nepalese norms, these findings show that the lower incisors are proclined but normally positioned which contradicts with the findings of Hunter ${ }^{11}$ in which it was found that retroclined lower incisor as a strong component of the class II malocclusion. Study done by Hitchcock ${ }^{19}$ however showed that the position of the lower incisor in Class II Div 1 samples was not significantly different than the class I samples and this is similar to the findings of this study.

Criag $^{20}$, Wylie $^{23}$, Sasauouni ${ }^{24}$ and Moyers et al ${ }^{25}$ have also noted wide variation in the size and shape of the various components of the craniofacial complex in Class II individuals. This study results indicate that retrusion of the mandible is the most commonly occurring factors contributing to class II malocclusion. Other studies done by Hunter ${ }^{11}$,Hitchcock ${ }^{19}$, Ishii $\mathrm{N}^{5,6}$ also support the findings of this study.

The measured position of the maxillary skeletal component in class II malocclusion was also shown in this study to be quite variable. The average position of the maxilla was found not to be statistically significant and can be considered to be neutral relative to cranial base structures.

Table 4. Comparison of class II Females with the Caucasian Norms:

\begin{tabular}{|c|c|c|c|c|}
\hline Parameters & $\begin{array}{l}\text { Caucasian } \\
\text { Normal }\end{array}$ & $\begin{array}{l}\text { Class II } \\
\text { Nepalese }\end{array}$ & & P Value \\
\hline $\begin{array}{l}\text { Effective maxillary } \\
\text { Length (mm) }\end{array}$ & 91.00 & 89.46 & 3.29 & $*$ \\
\hline $\begin{array}{l}\text { Effective mandibular } \\
\text { length }(\mathrm{mm})\end{array}$ & 120.20 & 114.13 & 4.59 & $* * *$ \\
\hline $\begin{array}{l}\text { Maxillo-mandibular } \\
\text { difference }(\mathrm{mm})\end{array}$ & 29.20 & 25.33 & 4.35 & $* * *$ \\
\hline $\begin{array}{l}\text { Upper Incisor to } \\
\text { Point A (mm) }\end{array}$ & 5.40 & 6.10 & 1.37 & $* *$ \\
\hline $\begin{array}{l}\text { Lower incisor to A - } \\
\text { Pog }(\mathrm{mm})\end{array}$ & 2.70 & 6.03 & 3.37 & $* * *$ \\
\hline
\end{tabular}


Table 5. Comparison between Class II Nepalese Males and Females.

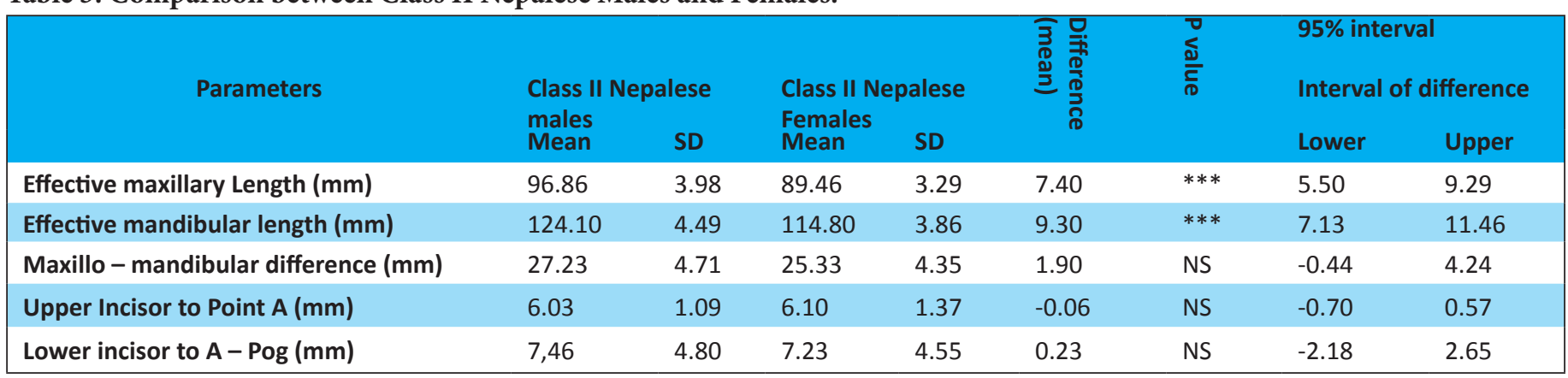

${ }^{\star} \mathbf{P}<.05 ;{ }^{* *} \mathrm{P}<.01 ;{ }^{* *} \mathrm{P}<.001$. Sig indicates significance; NS, not significant

\section{CONCLUSION}

Size of the mandible was found to be less than the norms which is the main cause of the Class II Div 1 pattern in Nepalese population. Prognathic maxilla with retrognathic upper incisors and retrognathic mandible with proclined lower incisors and was found to be the most common combinations of Class II Div 1. Class II Div 1 malocclusion is not a single entity and it can result from various combinations of skeletal, dental and soft tissue inter-relationships.

\section{REFERENCES}

1. Angle Edward H. Treatment of Malocclusion of the Teeth. In: Philadelphia: S. S. White Dental Mfg. Co;1907;p.103;chap. 4.

2. Ellis E, McNamara JA, Lawrence TM. Components of adult Class II open-bite malocclusion. J Oral Maxillofac Surg. 1985;43(2):92-105.

3. Bhattarai P. Steiner's cephalometrics analysis of Nepalese adults aged 18-30 years. J Nepal Dent Assoc. 2005;7(1):1-9.

4. Rajbhandari A. Cephalometric analysis of Nepalese adults (aged 17-30 years) using Down's analysis. J Nepal Dent Assoc. 2005;7(1):15-26.

5. Ishii N, Deguchi T, Hunt NP. Craniofacial morphology of Japanese girls with Class II division 1 malocclusion. J Orthod. 2001;28(3):211-5.

6. Ishii N, Deguchi T, Hunt NP. Morphological differences in the craniofacial structure between Japanese and Caucasian girls with Class II Division 1 malocclusions. Eur J Orthod. 2002;24(1):61-7.

7. Shindoi JM, Matsumoto Y, Sato Y, Ono T, Harada K. Soft Tissue Cephalometric Norms for Orthognathic and Cosmetic Surgery. J Oral Maxillofac Surg. 2013;71(1):e24-30.

8. Ousehal L, Lazrak L, Chafii A. Cephalometric norms for a Moroccan population. Int Orthod. 2012;10(1):122-34.

9. Farishta S, Varma DP, Reddy KS, Chandra S, Nanda Z. Cephalometric evaluation-based on Steiner's analysis on young adults of Chhattisgarh, India. J Contemp Dent Pract. 2011;12(3):174-8.

10. Reidel RA. The relation of maxillary structures to cranium in malocclusion and I normal occlusion. Angle Orthod. 1952;22:142-45. 11. Hunter WA. The vertical dimension of the face and skeletodental retrognathism. Am J Orhod. 1967;53:586-95.

12. Altemus LA. Cephalofacial relationships. Angle Orthod. 1968;38(3):175-84.

13. Delrich RC. A cephalometric study of untreated class II, Division 1 Malocclusion. Angle Orthod. 1948(18):70-4.

14. Rothstein TL. Facial morphology and growth from 10 to 14 years of age in children presenting Class II, Division 1 Malocclusion: a comparative roentgenographic cephalometric study. Am J Orthod., 1971;60(6):619-20. 15. Al-Khateeb EA, Al-Khateeb SN. Anteroposterior and vertical components of class II division 1 and division 2 malocclusion. Angle Orthod. 2009;79(5):859-66.

16. Riesmeijer AM, Prahl-Andersen B, Mascarenhas AK, Joo BH, Vig KW. A comparison of craniofacial Class I and Class II growth patterns. Am J Orthod Dentofacial Orthop. 2004;125(4):463-71.

17. Henry RG. A classification of class II division 1 malocclusion. Angle Orthod. 1957;27:83-92.

18. Harris JE, Kowalski CJ, Walker GF. Discrimination betweek normal and class II individuals using Steiner's analysis. Angle Orthod. 1972;42(3):212-20.

19. Hitchcock HP. A cephalometric description of Class II, Division 1 malocclusion. Am J Orthod. 1973;63(4):414-23.

20.C raig CE. The skeletal patterns characteristic of class I and class II, division I malocclusions in Norma Lataralis. Angle Orthod. 1951;21:4456.

21. Adams JW. Cephalometric studieson the form of the human mandible. Angle Orthod. 1948;18:8.

22. Renfroe EW. A study of facial patterns associated with class I, class II division 1 and class II division 2 maloccluison. Angle Orthod. 1948;19:1225.

23. Wylie WL. The assessment of Anteropostetior Dysplasia. Angle Orthod. 1948;17:97-109.

24. Sassouni V. A classification of skeletal facial types. Am J Orthod. 1969;55(2):109-23.

25. Moyers RE, Riolo ML, Guire KE, Wainright RL, Bookstein FL. Differential diagnosis of class II malocclusions. Part 1. Facial types associated with class II malocclusions. Am J Orthod. 1980;78(5):477-94. 